\title{
Calibration on MEPDG Low Temperature Cracking Model and Recommendation on Asphalt Pavement Structures in Seasonal Frozen Region of China
}

\author{
Hongyan Ma, Dongsheng Wang, Changjun Zhou, and Decheng Feng \\ School of Transportation Science and Engineering, Harbin Institute of Technology, Harbin 150090, China \\ Correspondence should be addressed to Decheng Feng; fengdecheng@hit.edu.cn
}

Received 1 March 2015; Accepted 7 June 2015

Academic Editor: Robert Cerný

Copyright (C) 2015 Hongyan Ma et al. This is an open access article distributed under the Creative Commons Attribution License, which permits unrestricted use, distribution, and reproduction in any medium, provided the original work is properly cited.

In order to implement the Mechanistic-Empirical Pavement Design Guide (MEPDG) to design and maintain asphalt pavements in China, it is necessary to calibrate transfer functions of distresses in MEPDG with local conditions, including traffics, environment, and materials as well as measured pavement distresses data in field. Comprehensive single factor sensitivity analyses of factors that influence thermal cracking of asphalt pavements were conducted utilizing the MEPDG low temperature cracking (LTC) model. Additionally, multiple factor sensitivity analyses were carried out as well, based on which pavement structures with sound thermal cracking resistance were recommended for seasonal frozen regions in China. Finally, the field data of thermal cracks on typical asphalt pavements in China was utilized to calibrate the LTC model in MEPDG. An improvement was proposed on MEPDG LTC model, after which was applied, the predicted thermal cracking from MEPDG LTC model agrees well with measured thermal cracking in China.

\section{Introduction}

Asphalt concrete is a typical viscoelastic plastic material. Thermal cracking may occur when temperature of asphalt concrete changes repeatedly or when there is temperature gradient inside asphalt concrete [1]. The thermal cracking forms pathways for intrusion of water and chemical ions into the pavement structure, which weakens the stiffness of subgrade and the capacity of asphalt pavement. Additionally, the existence of thermal cracks accelerates the aging of asphalt concrete and asphalt pavement distresses [2]. Therefore, it is of great importance to ensure that thermal cracking of asphalt pavement can be evaluated accurately, based on which asphalt pavement with sound resistance of thermal cracking can be designed.

Several models were proposed to predict thermal cracking on asphalt pavements in the last several decades. Hajek and Haas [3] developed a mathematical model based on field survey, which is capable of predicting the cracking frequency on asphalt pavement in service life. The variables involved in this model include stiffness of the original asphalt cement, winter design temperature, subgrade soil type, asphalt layer thickness, and pavement page since being built. Fromm and Phang [4] utilized factor analysis, multiple linear regression, and stepwise multiple regression to develop a model describing the observed phenomena and to predict cracking behavior of pavements. They claimed that the transverse cracking is more severe in areas with high freezing index. Other existing models predict cracking potential of asphalt mixture $[5,6]$ and cannot predict amount of cracks versus time. THERM [7] describes thermal cracking growth and spacing based on fracture mechanics. Jenq and Perng [8] proposed the cohesive cracking model to simulate the progressive cracking development in asphalt concrete, which is similar to the Dugdale-Barenblatt model. The model [8] covers basic mechanical properties of asphalt concrete, including tensile strength, fracture energy, and the stress-separation relation. Soares et al. [9] presented a numerical method based on the theory of fracture mechanics, in which binder and aggregates are treated as distinct materials and cracking propagation under monotonic loading was investigated. Jongeun and Imad [10] applied the fracture mechanics to analyze 
the reflection cracking in asphalt overlay with a finite element model utilizing the cohesive zone model. Kim et al. [11] was evaluated with respect to asphalt pavement performances of crack resistance in laboratory. Fazaeli et al. [12] evaluated the performance of modified bitumen at low temperatures based on Strategic Highway Research Program (SHRP) Superpave tests.

A universal problem exists in the above mentioned prediction models of thermal cracking. That is, the coupled effects of factors such as pavement structure and material properties on thermal cracking of asphalt mixture are not sufficiently considered. Prior to the Strategy Highway Research Program (SHRP) A-005 project, no existing models predicted thermal cracking performance (amount of cracking versus time) with fundamental, low temperature mixture properties [13]. Therefore, the SHRP A-005 program developed a new low temperature cracking (LTC) model that predicts thermal cracking (amount of cracking versus time) using properties of asphalt mixture measured from the indirect tensile (IDT) test (ASTM D6931-12) along with site-specific environmental and structural information [14]. The amount of crack propagation induced by a given thermal cooling cycle is predicted with the Paris Law of crack propagation [15]. Based on the results presented for a limited number of SPS-1 and SPS-9 projects, it is concluded that the nationally calibrated MEPDG transverse cracking model predicted transverse cracking adequately on this limited scale [16].

In order to implement the Mechanistic-Empirical Pavement Design Guide (MEPDG) to design and maintain asphalt pavements, numerous studies were conducted to evaluate and/or locally calibrate the MEPDG software [13, 17-22].

The climate, traffic, materials, and pavement structures between China and USA are significantly different. In particular, the semirigid base is widely used in China, which is not a common choice for USA. Therefore, local calibration is necessary on LTC model prior to the implementation of MEPDG in China. Additionally, the resistance of thermal cracking for typical asphalt pavements can be investigated in MEPDG software, based on which pavement structures with good resistance on thermal cracking can be recommended.

It is worth mentioning that this study was conducted with MEPDG software version 1.1 prior to the release of AASHTOWare Pavement Mechanistic-Empirical Design. Since the transfer functions of thermal cracking in the two softwares remain the same, the study in this paper is still valid and is helpful in designing asphalt pavements with sound thermal cracking resistance.

\section{Objectives and Scope}

The objectives of this paper is to propose typical pavement structures so that good resistance on thermal cracking for asphalt pavements can be obtained and to make the MEPDG LTC model proper to predict thermal cracking on asphalt pavement in the seasonal frozen region in China. First, the influences of factors on thermal cracking of asphalt pavement were analyzed through sensitivity analyses, including design temperature, structural layer thickness, types of base and subgrade, and void content of asphalt pavement. And then

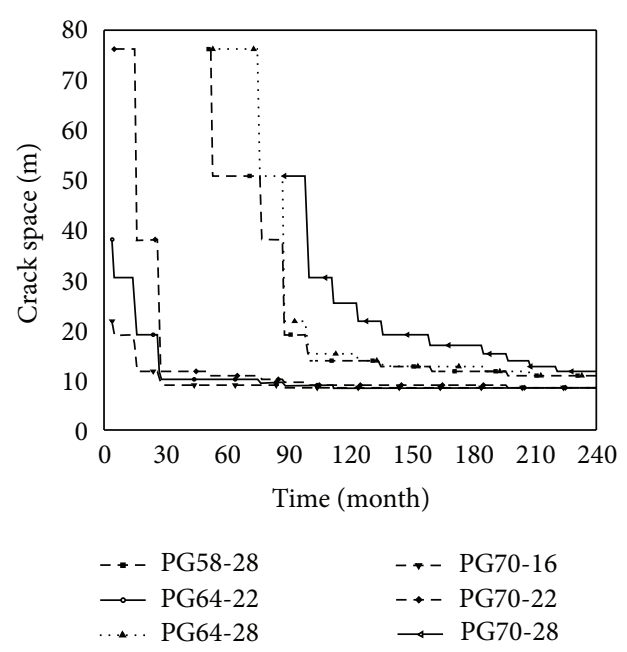

FIGURE 1: Influence of performance grade of asphalt binder on thermal cracking space on asphalt pavement.

asphalt pavement structures with sound resistance of thermal cracking were recommended. Finally, surveyed thermal cracking data in field from the seasonal frozen region of China was utilized to calibrate the MEPDG LTC model.

\section{Single Factor Sensitivity Analysis}

Sensitivity analyses on factors influencing thermal cracking space on asphalt pavement were carried out in MEPDG, including design temperature, layer thickness, types of base and subgrade, and air voids of asphalt concrete. The cracking space was defined by distance between the adjoining cracks. The level 3 inputs for materials were used.

3.1. Performance Grade of Asphalt Binder. Asphalt binders with varied Performance Grades influence thermal cracking space of asphalt pavements, as shown in Figure 1. It can be seen that the lower the design temperature for thermal cracking, the longer the thermal cracking space. Additionally, the initial time of thermal cracking delays as the design temperature for thermal cracking becomes lower.

3.2. Asphalt Layer Thickness. The control pavement structure has a $4 \mathrm{~cm}$ HMA16 surface layer, a $5 \mathrm{~cm}$ HMA20 intermediate layer, and a $6 \mathrm{~cm}$ HMA25 bottom layer of asphalt concrete, individually. HMA16 represents a hot mix asphalt (HMA) with a $16 \mathrm{~mm}$ nominal maximum aggregate. It is worth noting that the nominal maximum aggregate of $16 \mathrm{~mm}$ is not defined in USA. However, the HMA16 or SMA16 (SMA is Stone Matrix Asphalt) is the most popular type of asphalt mixture in China. The aggregate gradation of HMA16 was put into MEPDG according to the sieve analyses in laboratory. Then three other pavement structures were produced by increasing the thickness of each asphalt layer 1.25 times each time, respectively. It indicates from Figures 2-4 that increasing the thickness of surface asphalt layer can most effectively postpone the initial time of thermal cracking and increase 


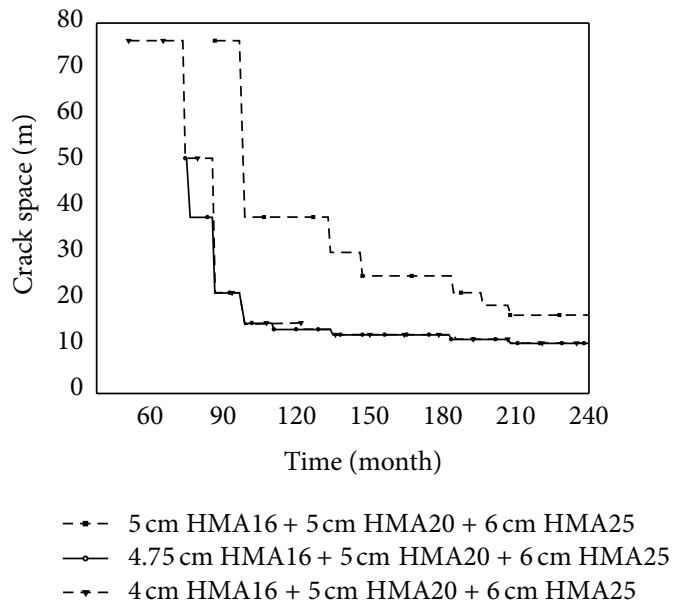

FIGURE 2: Influence of asphalt surface layer thickness on thermal cracking space on asphalt pavement.

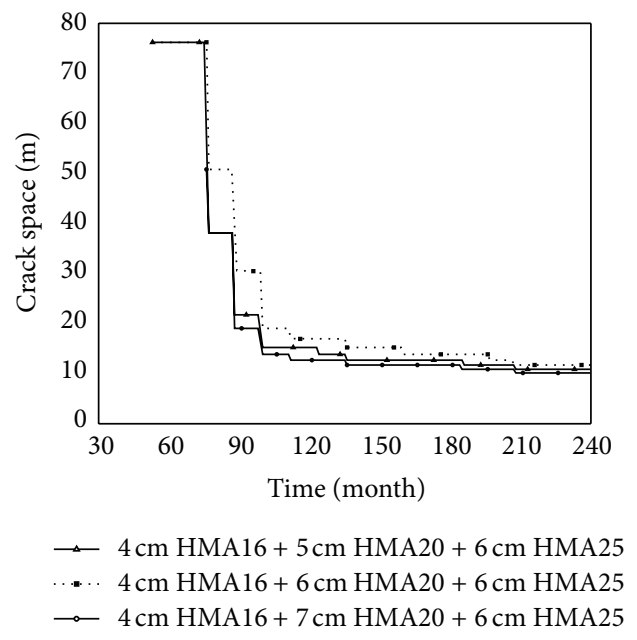

FIGURE 3: Influence of asphalt intermediate layer thickness on thermal cracking space on asphalt pavement.

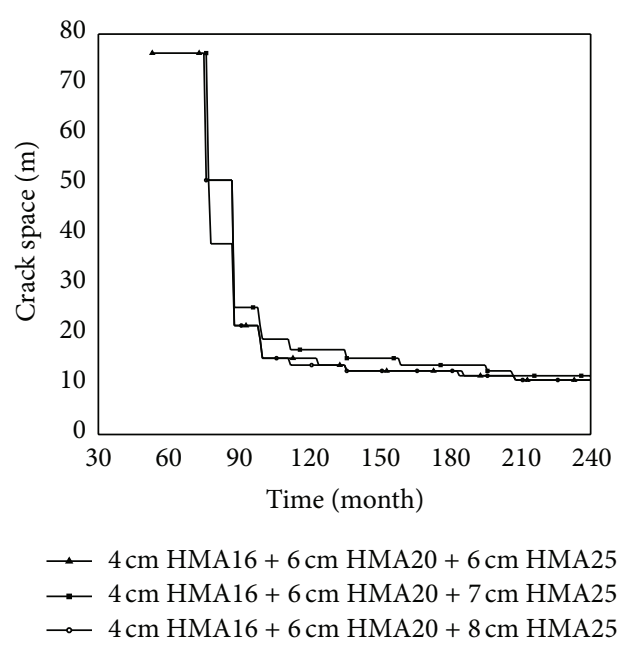

FIGURE 4: Influence of asphalt bottom layer thickness on thermal cracking space on asphalt pavement.

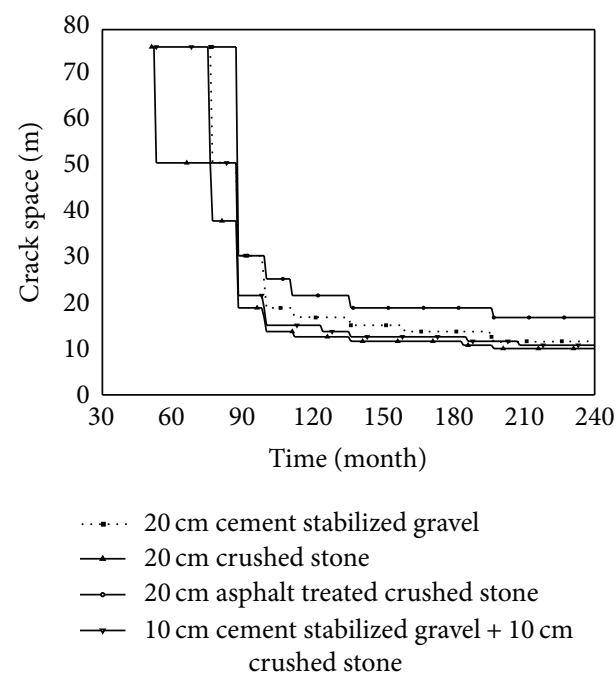

Figure 5: Influence of base type on thermal cracking space on asphalt pavement.

the thermal cracking space. It seems that there is no change on thermal cracking when increasing the thickness of bottom layer, as shown in Figure 4. Therefore, when increasing layer thickness is an option to improve the thermal cracking resistance of asphalt pavement, the most effective way is to increase the thickness of surface asphalt layer.

3.3. Base Type. In order to investigate the influence of base type on thermal cracking on asphalt pavement, four types of base were selected, while all other factors remain the same. Figure 5 shows the thermal cracking space on asphalt pavement. It is shown that in the first 7 years asphalt pavement with asphalt treated crushed stone base has the largest thermal cracking space, followed by asphalt pavement with cement stabilized base and the combined base, that is, $22 \mathrm{~cm}$ graded crushed stone (GCS) underneath $10 \mathrm{~cm}$ cement stabilized gravel (CSG). The worst base type in the first 7 years on resisting thermal cracking is graded crushed stone. However, after 7 years, there are nearly no differences among thermal cracking spaces from asphalt pavements except the one with asphalt treated crushed stone base, which behaves slightly better than the others. Considering the construction cost and construction speed, the combined base is recommended.

3.4. Subgrade Type. Eight default types of subgrade were investigated on their effects on thermal cracking on asphalt pavement. It can be seen from Figure 6 that the thermal cracking of asphalt pavement is not sensitive to subgrade type.

It is worth mentioning that in China the high-filled subgrade is most widely used, which is different from the subgrade in USA. The thermal cracking is expected to be more severe on asphalt pavements in China. Without the protection of surrounding soils, the thermal cracking of asphalt pavement should be more sensitive to subgrade type 


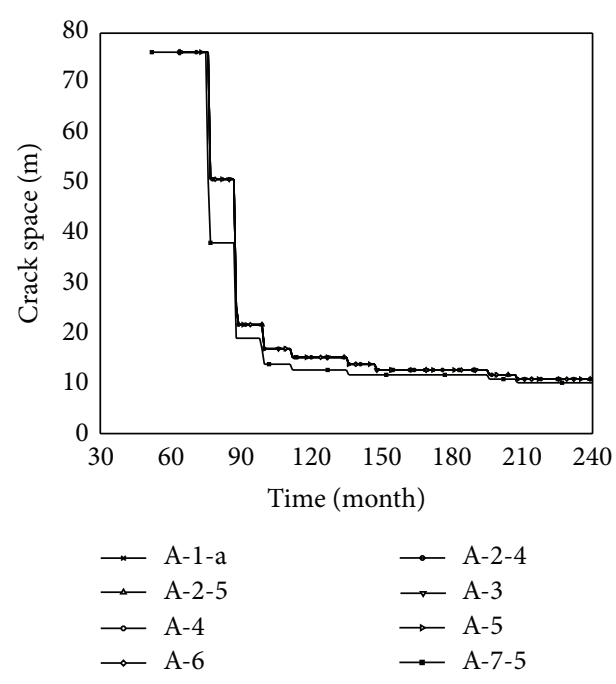

FIGURE 6: Influence of subgrade type on thermal cracking space on asphalt pavement.

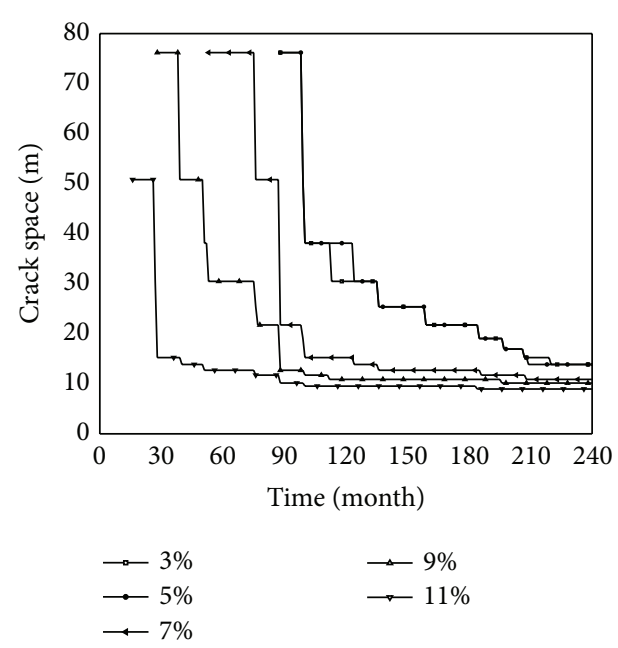

FIGURE 7: Influence of air voids in asphalt concrete on thermal cracking space on asphalt pavement.

than the case shown in Figure 6. However, such high-filled subgrade is not considered in MEPDG.

3.5. Air Voids of Asphalt Concrete. When the air voids of asphalt concrete increase in the range of $5-11 \%$, the thermal crack space on asphalt pavement increases, as shown in Figure 7. However, when the air void is lower than $5 \%$, the influence of air void of asphalt concrete on thermal cracking seems ignorable.

\section{Multiple Factor Sensitivity Analysis}

In order to investigate the influence of pavement structures on the thermal cracking resistance of asphalt concrete, 36 different pavement structures generated from six combinations of asphalt layers (Table 1) and six combinations of
TABLE 1: Combinations of asphalt layers for multiple factor sensitivity analysis.

\begin{tabular}{lccc}
\hline Symbol & \multicolumn{3}{c}{ Combination of asphalt layers } \\
\hline A & $5 \mathrm{~cm} \mathrm{HMA16}$ & - & - \\
B & $5 \mathrm{~cm} \mathrm{HMA16}$ & - & $5 \mathrm{~cm} \mathrm{HMA25}$ \\
C & $5 \mathrm{~cm} \mathrm{HMA16}$ & $5 \mathrm{~cm} \mathrm{HMA20}$ & $5 \mathrm{~cm} \mathrm{HMA25}$ \\
D & $4 \mathrm{~cm} \mathrm{HMA16}$ & $5 \mathrm{~cm} \mathrm{HMA20}$ & $6 \mathrm{~cm} \mathrm{HMA25}$ \\
E & $6 \mathrm{~cm} \mathrm{HMA16}$ & $5 \mathrm{~cm}$ HMA20 & $4 \mathrm{~cm} \mathrm{HMA25}$ \\
F & $4 \mathrm{~cm} \mathrm{HMA16}$ & $7 \mathrm{~cm} \mathrm{HMA20}$ & $4 \mathrm{~cm} \mathrm{HMA25}$ \\
\hline
\end{tabular}

Note: HMA16, HMA20, and HMA25 present HMA mixtures with the nominal maximum aggregate sizes of $16 \mathrm{~mm}, 20 \mathrm{~mm}$, and $25 \mathrm{~mm}$, respectively.

TABLE 2: Base combinations for multiple factor sensitivity analysis.

\begin{tabular}{ll}
\hline Symbol & Combination of base layers \\
\hline a & $20 \mathrm{~cm}$ cement stabilized gravel \\
b & $20 \mathrm{~cm}$ crushed stone \\
$\mathrm{c}$ & $20 \mathrm{~cm}$ asphalt treated crushed stone \\
$\mathrm{d}$ & $10 \mathrm{~cm}$ cement stabilized gravel $+10 \mathrm{~cm}$ crushed stone \\
e & $8 \mathrm{~cm}$ cement stabilized gravel $+12 \mathrm{~cm}$ crushed stone \\
$\mathrm{f}$ & $12 \mathrm{~cm}$ cement stabilized gravel $+8 \mathrm{~cm}$ crushed stone \\
\hline
\end{tabular}

TABLE 3: Recommended asphalt pavement structures.

\begin{tabular}{lcccccc}
\hline \multirow{2}{*}{ aase layers } & A & B & C & D & E & F \\
\hline a & $\sqrt{ }$ & $\sqrt{ }$ & $\sqrt{ } \sqrt{ }$ & $\sqrt{ }$ & $\times$ & $\times$ \\
b & $\times$ & $\times$ & $\times$ & $\times$ & $\times$ & $\times$ \\
c & $\sqrt{ } \sqrt{ }$ & $\sqrt{ } \sqrt{ }$ & $\sqrt{ } \sqrt{ }$ & $\sqrt{ }$ & $\sqrt{ } \sqrt{ }$ & $\sqrt{ }$ \\
d & $\sqrt{ }$ & $\sqrt{ } \sqrt{ }$ & $\sqrt{ } \sqrt{ }$ & $\sqrt{ }$ & $\sqrt{ }$ & $\times$ \\
e & $\sqrt{ }$ & $\sqrt{ } \sqrt{ } \sqrt{ }$ & $\sqrt{ } \sqrt{ }$ & $\sqrt{ }$ & $\sqrt{ }$ & $\times$ \\
f & $\sqrt{ } \sqrt{ }$ & $\sqrt{ } \sqrt{ } \sqrt{ } \sqrt{ }$ & $\sqrt{ } \sqrt{ }$ & $\sqrt{ }$ & $\times$ & $\times$ \\
\hline
\end{tabular}

bases (Table 2) were analyzed from MEPDG software 1.1. The predicted thermal cracking was shown in Figures 8 and 9. From the comparisons between Figures 8 and 9, the recommended pavement structures were summarized in Table 3 . The recommendation of asphalt structures was based on two criteria: (1) the initial time and thermal cracking space and (2) the construction cost. It can be seen from Table 3 that asphalt pavement structure $B+f$ is the first recommended pavement structure, followed by $\mathrm{B}+\mathrm{e}$ and then $\mathrm{B}+\mathrm{c}, \mathrm{A}+\mathrm{c}$, and $\mathrm{C}+\mathrm{c}$.

\section{Calibration on LTC Model}

Three typical highway asphalt pavements in northeast area of China were selected to calibrate the LTC model in MEPDG, including Qitai Highway and Haxihuan Highway in Heilongjiang and Changping Highway in Jilin. The thermal cracking data on these asphalt pavements was collected.

5.1. Data Preparation. Qitai, Haxihuan, and Changping Highways were built in 2009, 1996, and 1996, respectively. Traffic was opened in September or October in the same year, respectively. 

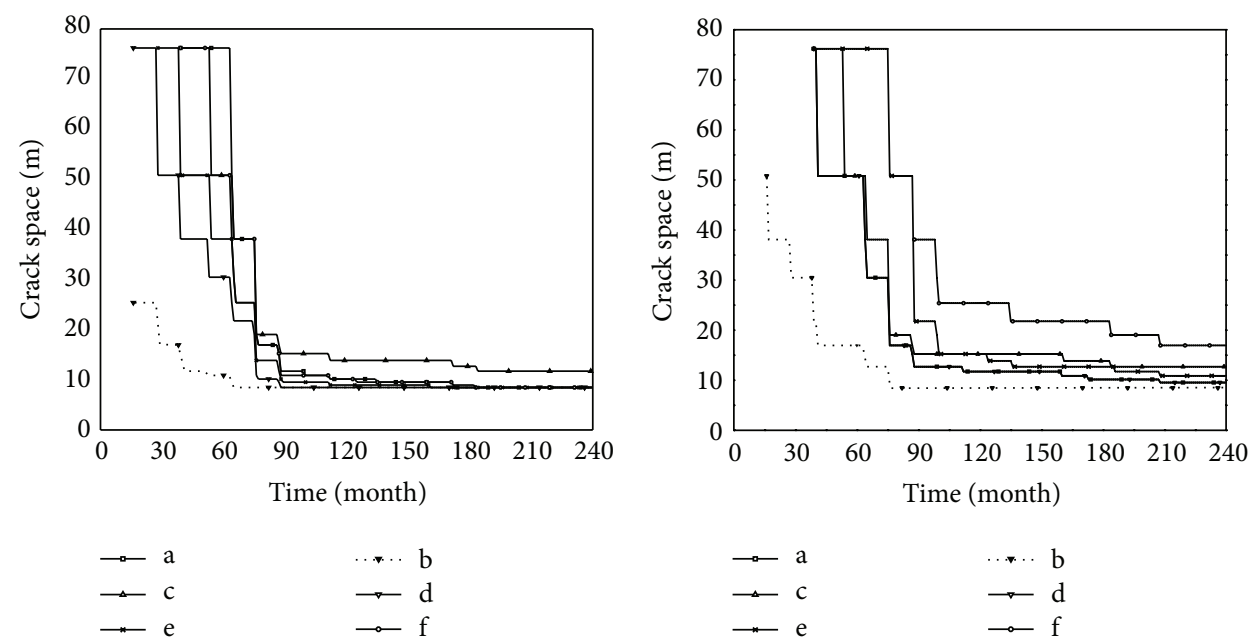

(a) $5 \mathrm{~cm}$ HMA16
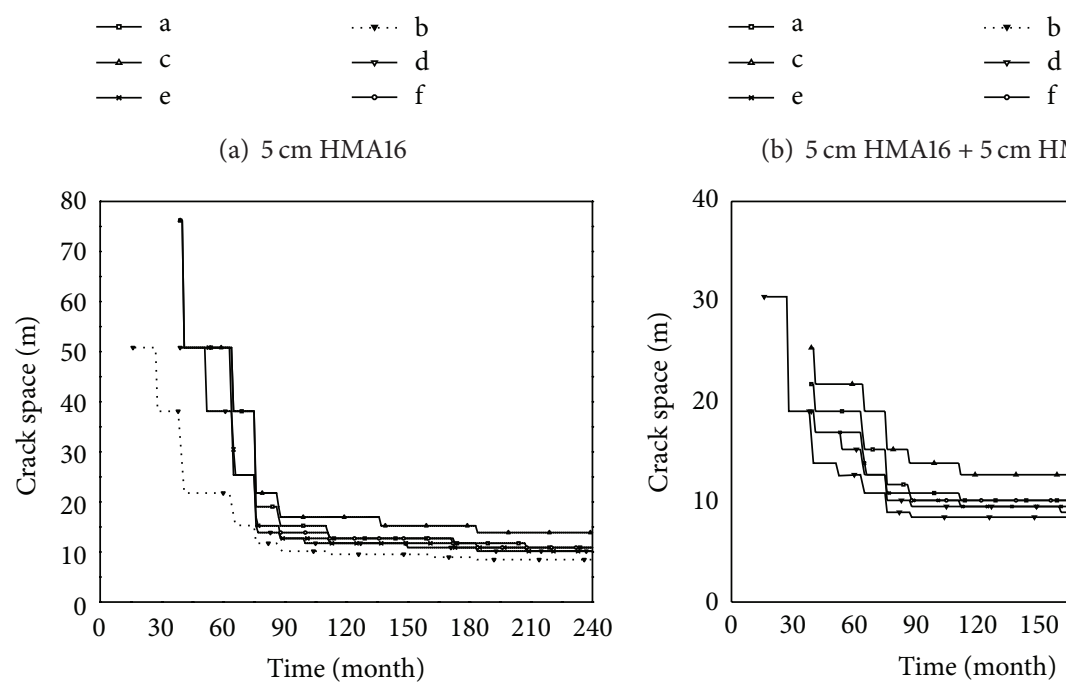

(b) $5 \mathrm{~cm} \mathrm{HMA16}+5 \mathrm{~cm} \mathrm{HMA25}$
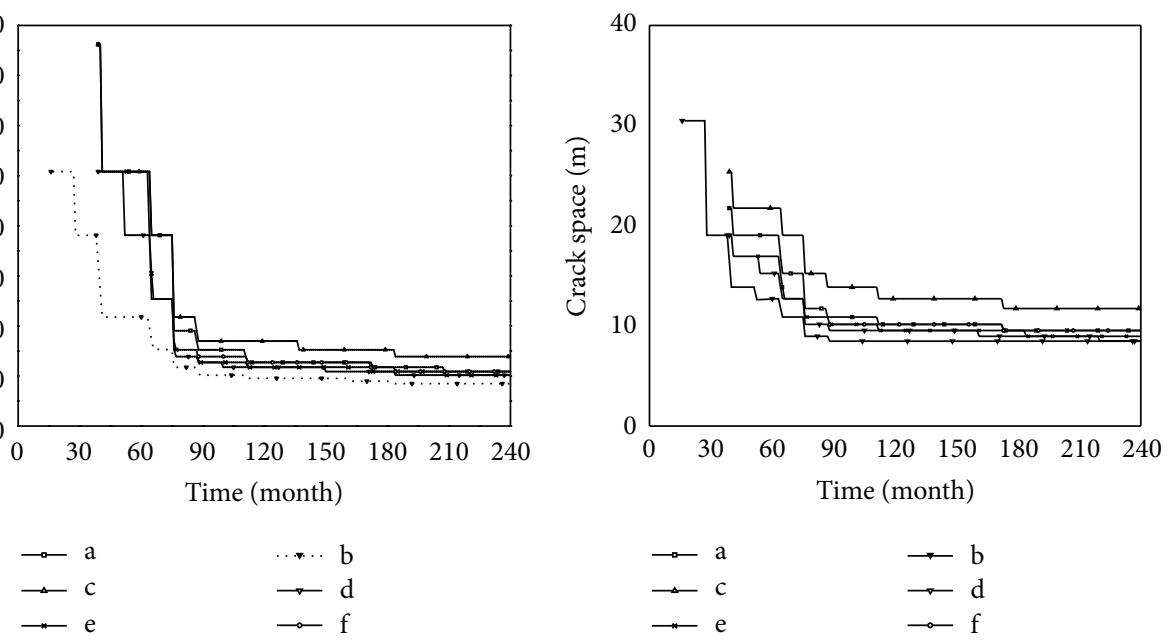

(c) $5 \mathrm{~cm} \mathrm{HMA} 16+5 \mathrm{~cm} \mathrm{HMA20}+5 \mathrm{~cm}$ HMA25

(d) $4 \mathrm{~cm} \mathrm{HMA16}+5 \mathrm{~cm} \mathrm{HMA20} \mathrm{+} 6 \mathrm{~cm}$ HMA25
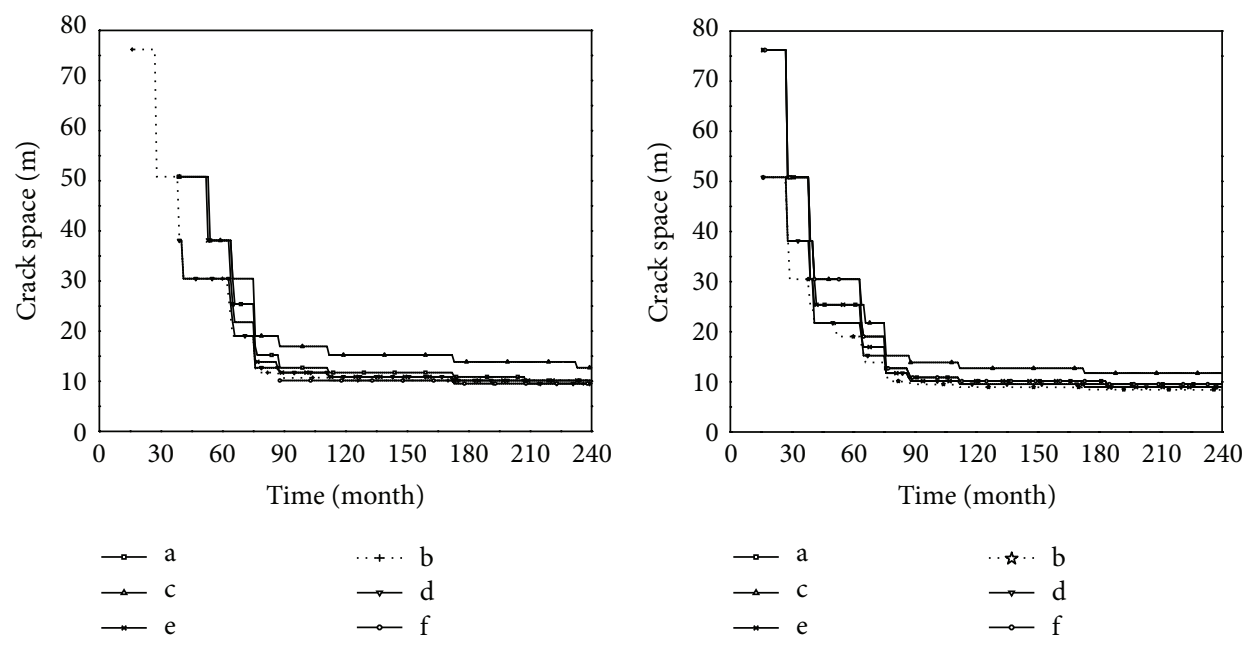

(e) $6 \mathrm{~cm} \mathrm{HMA16}+5 \mathrm{~cm}$ HMA20 + $4 \mathrm{~cm}$ HMA25
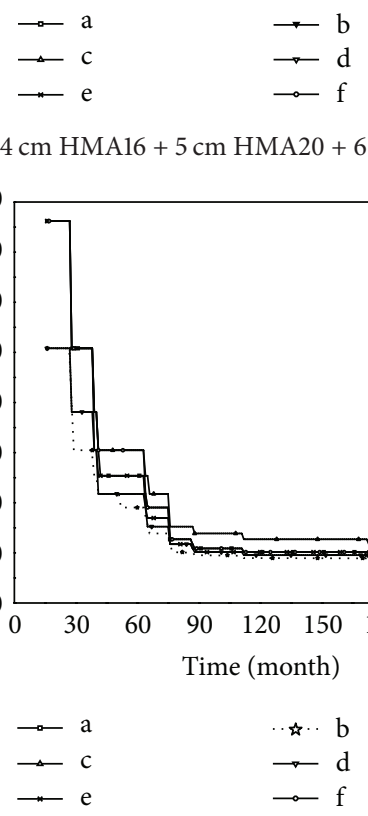

(f) $4 \mathrm{~cm} \mathrm{HMA16}+7 \mathrm{~cm} \mathrm{HMA20}+4 \mathrm{~cm} \mathrm{HMA} 25$

FiguRE 8: Thermal cracking development of asphalt pavements with different asphalt layers. Note: the terms "a," "b," "c," "d," "e," and "f" were defined in Table 2. 


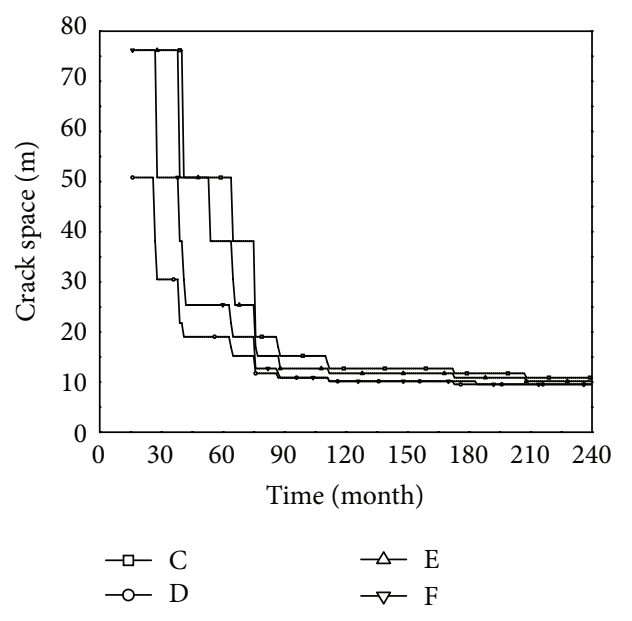

(a) $20 \mathrm{~cm}$ cement stabilized gravel
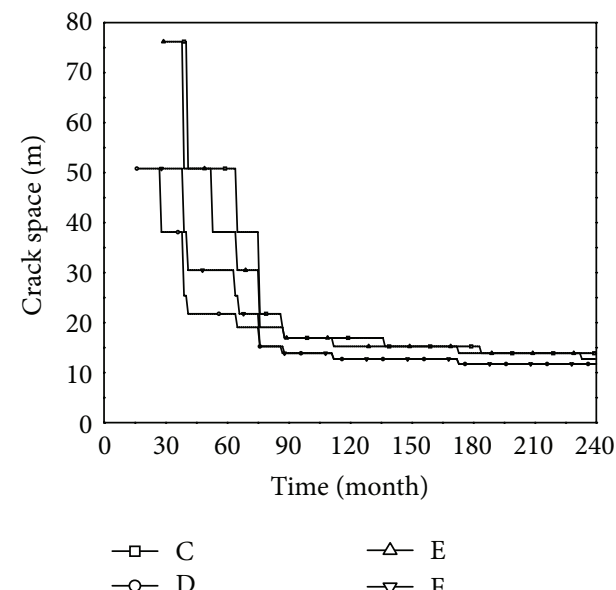

(c) $20 \mathrm{~cm}$ asphalt treated crushed stone
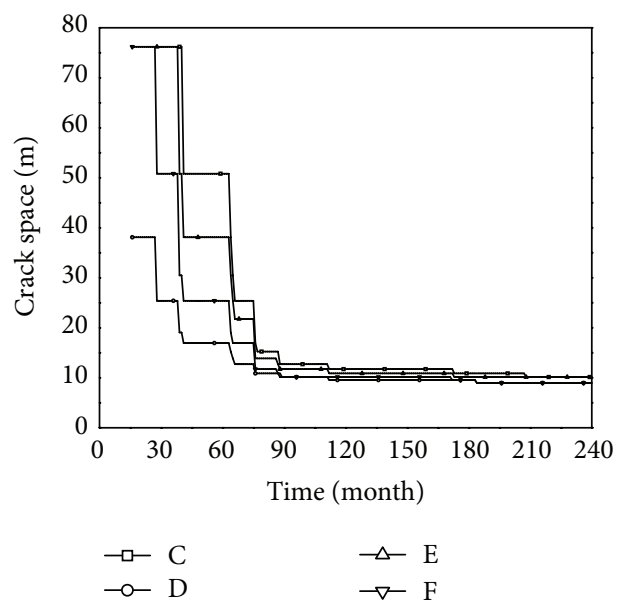

(e) $8 \mathrm{~cm}$ cement stabilized gravel $+12 \mathrm{~cm}$ crushed stone
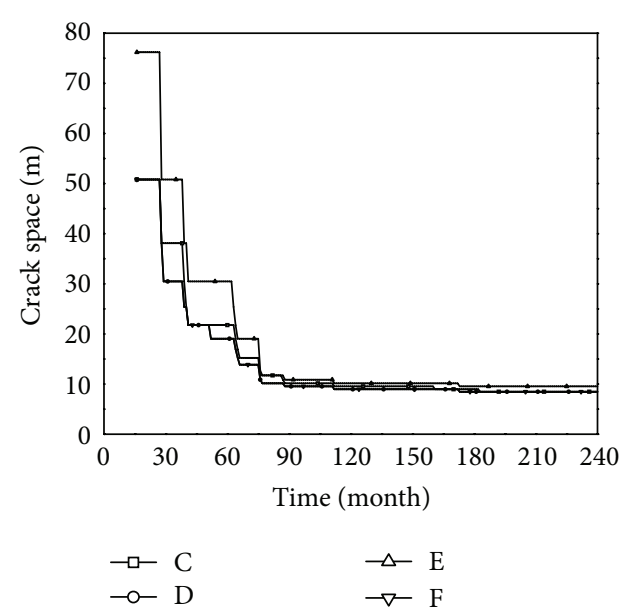

(b) $20 \mathrm{~cm}$ crushed stone
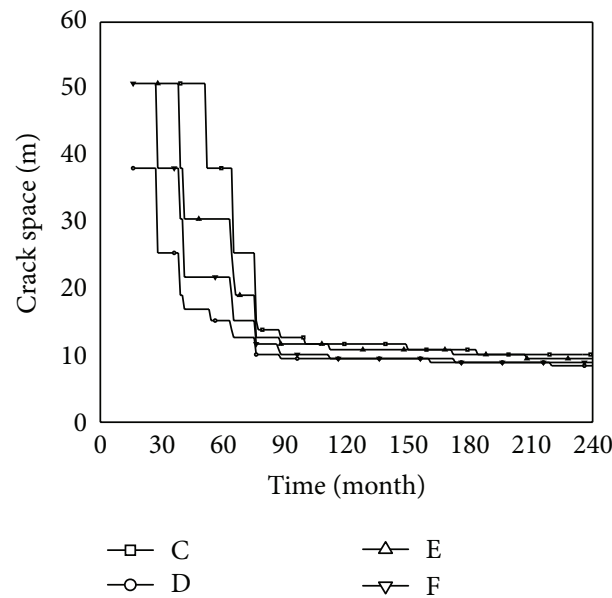

(d) $10 \mathrm{~cm}$ cement stabilized gravel $+10 \mathrm{~cm}$ crushed stone

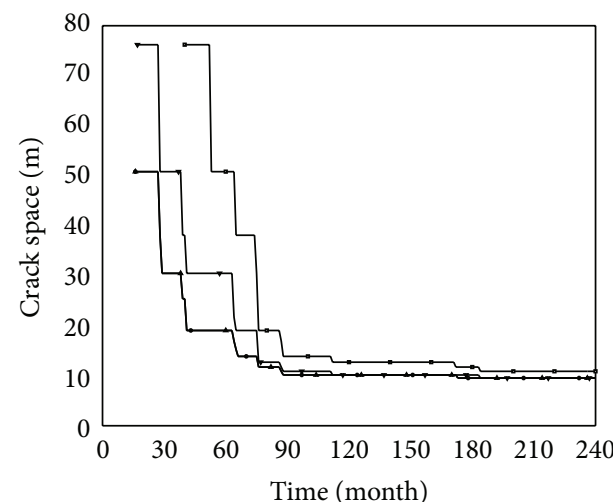

(f) $12 \mathrm{~cm}$ cement stabilized gravel $+8 \mathrm{~cm}$ crushed stone

FIGURE 9: Thermal cracking development of asphalt pavements with different base combinations. Note: the terms "C," "D," "E," and "F" were defined in Table 1. 
TABle 4: Average temperatures in climate station [23].

\begin{tabular}{lcccccc}
\hline Station & $\begin{array}{c}\text { Shenyang, } \\
\text { China }\end{array}$ & $\begin{array}{c}\text { Qiqihar, } \\
\text { China }\end{array}$ & Yanji, China & $\begin{array}{c}\text { Hailar, } \\
\text { China }\end{array}$ & $\begin{array}{c}\text { Bismarck, North } \\
\text { Dakota }\end{array}$ & $\begin{array}{c}\text { Omaha, } \\
\text { Nebraska }\end{array}$ \\
\hline Avg. temp of Jan. $\left({ }^{\circ} \mathrm{C}\right)$ & -11.5 & -19.2 & -14 & -26.2 & -12.7 & -6.4 \\
Avg. temp of Jul. $\left({ }^{\circ} \mathrm{C}\right)$ & 24.5 & 22.8 & 21.2 & 19.7 & 21.3 & 24.7 \\
\hline \multirow{2}{*}{ Station } & $\begin{array}{c}\text { Duluth, } \\
\text { Minnesota }\end{array}$ & $\begin{array}{c}\text { Fairbanks, } \\
\text { Alaska }\end{array}$ & $\begin{array}{c}\text { International } \\
\text { Falls, Minnesota }\end{array}$ & $\begin{array}{c}\text { St. Louis, } \\
\text { Missouri }\end{array}$ & $\begin{array}{c}\text { Memphis, } \\
\text { Tennessee }\end{array}$ & $\begin{array}{c}\text { Miami, } \\
\text { Florida }\end{array}$ \\
\hline Avg. temp of Jan. $\left({ }^{\circ} \mathrm{C}\right)$ & -13.5 & -23.4 & -17.2 & -1.5 & 4.3 & 28.1 \\
Avg. temp of Jul. $\left({ }^{\circ} \mathrm{C}\right)$ & 18.9 & 16.9 & 19.3 & 26.6 & 28.1 \\
\hline
\end{tabular}

TABLE 5: Water table in Heilongjiang and Jilin.

\begin{tabular}{lccc}
\hline Station & Max water level & Mix water level & Avg. water level \\
\hline Harbin & $110.04 \mathrm{~m}$ & $104.90 \mathrm{~m}$ & $107.35 \mathrm{~m}$ \\
Changchun & $209.44 \mathrm{~m}$ & $197.80 \mathrm{~m}$ & $201.01 \mathrm{~m}$ \\
Daqing & $153.97 \mathrm{~m}$ & $150.40 \mathrm{~m}$ & $152.08 \mathrm{~m}$ \\
Spring & $162.80 \mathrm{~m}$ & $156.15 \mathrm{~m}$ & $158.88 \mathrm{~m}$ \\
\hline
\end{tabular}

5.1.1. Traffic. Some factors, such as axle load distribution and percentage of vehicles in the design lane, are very sensitive inputs [24]. Because detailed information about axle load distribution is still unavailable from the China pavement management system (PMS), national default axle load spectra were used in this study. The equivalent single axle load (ESAL) acquired from the PMS was selected as a traffic level indicator. The initial average annual daily truck traffic (AADTT) was back-calculated from the respective ESALs and determined as 3500 .

5.1.2. Climate. Climate stations in USA with similar latitudes and climate types were chosen for selected pavement sections. The climate stations have similar average temperatures in January and July to the corresponding temperatures in areas where the highways locate. The difference should be in the range of $-5^{\circ} \mathrm{C}$ to $5^{\circ} \mathrm{C}$. From the comparison of climates from China and USA in Tables 4-5, it is recommended that climate stations of Duluth, Minnesota; Bismarck, North Dakota; and International Falls, Minnesota were chosen as climate stations for Changping, Qitai, and Haxihuan highways, respectively.

According to the China geological environment information site [23], the groundwater table is $150 \mathrm{~m}$ deep or lower. Because distress predictions for asphalt pavement sections are not affected by depths greater than $1.2 \mathrm{~m}[25,26]$, the depth of groundwater table was assumed to be $150 \mathrm{~m}$ for all pavement sections.

5.1.3. Pavement Structures and Material Properties. Basic information on the location, structure, construction and maintenance history, and soil properties of the selected highway pavement sections is presented in Table 6.

The level 3 inputs were defined and used for the MEPDG analyses in this study. The gradation, air voids, optimum binder content, and performance grade of binder for asphalt layers were prepared at this level.
5.2. Determination of Initial Roughness Index. The initial roughness index (IRI) is one of the critical input parameters in the evaluation of the pavement roughness. The MEPDG recommends $99.4 \mathrm{~cm} / \mathrm{km}$ as an initial IRI. Present serviceability index is a roughness index in the AASHTO 1993 design guide [14]. For the convenience of communication with agencies that still use PSI as a roughness index in China and other regions, the MEPDG recommend IRI was used in this study to characterize pavement roughness.

\subsection{Comparison between Surveyed and Predicted Thermal Cracking}

5.3.1. Changping Highway. The surveyed cracking data on Changping Highway at 50 months after traffic opening was shown in Table 7. The cracking space in each surveyed section is different from each other. The surveyed cracking and the predicted cracking were plotted in Figure 10. It can be seen that the predicted thermal cracking occurred after 53 months since traffic opening with a cracking space of $76.2 \mathrm{~m}$. Then the predicted thermal cracking space decreased with time (50.8 $\mathrm{m}$ after 76 months, $21.8 \mathrm{~m}$ after 88 months, and $10.9 \mathrm{~m}$ after 208 months). The average surveyed thermal cracking space on Changping Highway is $20 \mathrm{~m}$ after 50 months since traffic opening, which is close to the predicted thermal cracking space at the 96th month since traffic opening.

5.3.2. Qitai Highway. The surveyed cracking data on Qitai Highway at 6 months after traffic opening was shown in Table 8. The surveyed cracking and predicted thermal cracking were plotted in Figure 11. It can be seen that the predicted thermal cracking occurred after 76 months since traffic opening with a cracking space of $50.8 \mathrm{~m}$. Then the predicted thermal cracking space decreased with time (25.4 $\mathrm{m}$ after 89 months and $12.9 \mathrm{~m}$ after 184 months). The average surveyed thermal cracking space on Qitai Highway was $34.4 \mathrm{~m}$ after 6 months since traffic opening, which is close to the predicted thermal cracking space at the 87 th month since traffic opening.

5.3.3. Haxihuan Highway. The surveyed cracking data on Haxihuan Highway after 30, 48, and 72 months since traffic opening was shown in Table 9. The surveyed cracking and the predicted thermal cracking were plotted in Figure 12. It can be seen that the predicted thermal cracking initiated at the 41st month since traffic opening with a cracking space of $76.2 \mathrm{~m}$. 
TABLE 6: Pavement structure and material information for the selected highways.

\begin{tabular}{|c|c|c|c|c|c|c|}
\hline Highway & Surface layer & $\begin{array}{l}\text { Intermediate } \\
\text { layer }\end{array}$ & Bottom layer & Base & Subbase & Subgrade \\
\hline Changping & $4 \mathrm{~cm}$ HMA16 & $\begin{array}{c}5 \mathrm{~cm} \text { HMA } \\
20\end{array}$ & $6 \mathrm{~cm}$ HMA25 & $\begin{array}{l}25 \mathrm{~cm} \text { lime and fly ash } \\
\text { treated crushed stone }\end{array}$ & $\begin{array}{c}25 \mathrm{~cm} \text { lime and fly ash } \\
\text { treated soil }\end{array}$ & $\begin{array}{l}30 \mathrm{~cm} \text { gravel }+ \\
\text { soil foundation }\end{array}$ \\
\hline Qitai & $5 \mathrm{~cm} \mathrm{HMA16}$ & - & $7 \mathrm{~cm}$ HMA20 & $\begin{array}{l}20 \mathrm{~cm} \text { cement stabilized } \\
\text { crushed stone }\end{array}$ & $\begin{array}{c}30 \mathrm{~cm} \text { cement } \\
\text { stabilized gravel }\end{array}$ & $\begin{array}{l}25 \mathrm{~cm} \text { gravel + } \\
\text { soil foundation }\end{array}$ \\
\hline Haxihuan & $4 \mathrm{~cm} \mathrm{HMA16}$ & $\begin{array}{c}6 \mathrm{~cm} \text { HMA } \\
20\end{array}$ & $7 \mathrm{~cm}$ HMA25 & $\begin{array}{c}20 \mathrm{~cm} \text { cement stabilized } \\
\text { gravel }\end{array}$ & $\begin{array}{l}33 \mathrm{~cm} \text { lime and fly ash } \\
\text { treated crushed stone }\end{array}$ & $\begin{array}{l}20 \mathrm{~cm} \text { gravel }+ \\
\text { soil foundation }\end{array}$ \\
\hline
\end{tabular}

TABLE 7: Surveyed data of thermal cracking on Changping Highway after 50 months since traffic opening.

\begin{tabular}{|c|c|c|c|c|}
\hline Stake mark & Distance $(\mathrm{km})$ & Crack number & Crack index & Crack space $(\mathrm{m})$ \\
\hline $\mathrm{K} 202+000 \sim \mathrm{K} 205+000$ & 3 & 18 & 0.6 & 176.5 \\
\hline $\mathrm{K} 273+000 \sim \mathrm{K} 275+000$ & 2 & 21 & 1.1 & 100.0 \\
\hline $\mathrm{K} 214+000 \sim \mathrm{K} 216+000$ & 2 & 61.6 & 3.1 & 33.0 \\
\hline $\mathrm{K} 259+000 \sim \mathrm{K} 261+000$ & 2 & 86.6 & 4.3 & 23.4 \\
\hline $\mathrm{K} 283+000 \sim \mathrm{K} 285+000$ & 2 & 67.2 & 3.4 & 30.2 \\
\hline $\mathrm{K} 208+000 \sim \mathrm{K} 210+000$ & 2 & 93.2 & 4.7 & 21.7 \\
\hline $\mathrm{K} 237+000 \sim \mathrm{K} 239+000$ & 2 & 135.5 & 6.8 & 14.9 \\
\hline $\mathrm{K} 239+700 \sim \mathrm{K} 240+300$ & 0.6 & 33.2 & 5.5 & 18.6 \\
\hline $\mathrm{K} 226+700 \sim \mathrm{K} 228+300$ & 1.6 & 181.1 & 11.3 & 8.9 \\
\hline $\mathrm{K} 248+000 \sim \mathrm{K} 250+000$ & 2 & 174.2 & 8.7 & 11.5 \\
\hline $\mathrm{K} 251+000 \sim \mathrm{K} 253+000$ & 2 & 163.7 & 8.2 & 12.3 \\
\hline
\end{tabular}

TABLE 8: Surveyed data of thermal cracking on Qitai Highway after 6 months since traffic opening.

\begin{tabular}{|c|c|c|c|c|c|}
\hline Stake mark & Distance $(\mathrm{km})$ & & Crack number & Crack index & Crack space $(\mathrm{m})$ \\
\hline \multirow{2}{*}{$\mathrm{K} 2+300 \sim \mathrm{K} 4+000$} & \multirow{2}{*}{1.7} & Plus & 54 & 3.2 & 31.5 \\
\hline & & Minus & 51 & 3.0 & 33.3 \\
\hline \multirow{2}{*}{$\mathrm{K} 39+000 \sim \mathrm{K} 41+000$} & \multirow{2}{*}{2} & Plus & 73 & 3.7 & 27.4 \\
\hline & & Minus & 53 & 2.7 & 37.7 \\
\hline \multirow{2}{*}{$\mathrm{K} 50+000 \sim \mathrm{K} 52+000$} & \multirow{2}{*}{2} & Plus & 65 & 3.3 & 30.8 \\
\hline & & Minus & 46 & 2.3 & 43.5 \\
\hline \multirow{2}{*}{$\mathrm{K} 84+000 \sim \mathrm{K} 86+000$} & \multirow{2}{*}{2} & Plus & 53 & 2.7 & 37.7 \\
\hline & & Minus & 56 & 2.8 & 35.7 \\
\hline \multirow{2}{*}{$\mathrm{K} 102+000 \sim \mathrm{K} 104+000$} & \multirow{2}{*}{2} & Plus & 41 & 2.1 & 48.8 \\
\hline & & Minus & 49 & 2.5 & 40.8 \\
\hline \multirow{2}{*}{$\mathrm{K} 130+000 \sim \mathrm{K} 132+000$} & \multirow{2}{*}{2} & Plus & 94 & 4.7 & 21.3 \\
\hline & & Minus & 82 & 4.1 & 24.4 \\
\hline
\end{tabular}

TABle 9: Surveyed data of thermal cracking on Haxihuan Highway since traffic opening.

\begin{tabular}{|c|c|c|c|c|c|c|c|c|c|c|}
\hline \multirow{2}{*}{ Milestone } & \multirow{2}{*}{ Dir. } & \multicolumn{3}{|c|}{ Crack number } & \multicolumn{3}{|c|}{ Crack index } & \multicolumn{3}{|c|}{ Crack space (m) } \\
\hline & & 30 mon. & 48 mon. & 72 mon. & 30 mon. & 48 mon. & 72 mon. & 30 mon. & 48 mon. & 72 mon. \\
\hline \multirow{2}{*}{ K46-K47 } & + & 20 & 30 & 30 & 2 & 2.7 & 3 & 52.6 & 38.5 & 34.5 \\
\hline & - & 22 & 27 & 42 & 2.2 & 3 & 4.2 & 47.6 & 34.5 & 24.4 \\
\hline \multirow{2}{*}{ K47-K48 } & + & 23 & 30 & 30 & 2.3 & 2.7 & 3 & 45.5 & 38.5 & 34.5 \\
\hline & - & 20 & 27 & 31 & 2 & 2.6 & 3.1 & 52.6 & 40.0 & 33.3 \\
\hline \multirow{2}{*}{ K48-K49 } & + & 15 & 26 & 25 & 1.5 & 2.1 & 2.5 & 71.4 & 50.0 & 41.7 \\
\hline & - & 17 & 21 & 25 & 1.7 & 2 & 2.5 & 62.5 & 52.6 & 41.7 \\
\hline \multirow{2}{*}{ K49-K50 } & + & 18 & 20 & 25 & 1.8 & 2.3 & 2.5 & 58.8 & 45.5 & 41.7 \\
\hline & - & 20 & 23 & 28 & 2 & 2.2 & 2.8 & 52.6 & 47.6 & 37.0 \\
\hline
\end{tabular}


TABLE 10: Initiation and latency of predicted thermal cracking.

\begin{tabular}{lccc}
\hline Pavement section & Changping Highway & Qitai Highway & Haxihuan Highway \\
\hline Initiation & $53 \mathrm{rd}$ & 76 th & 41 st \\
Latency & $\approx 48$ th & $\approx 80$ th & $\approx 40$ th \\
\hline
\end{tabular}

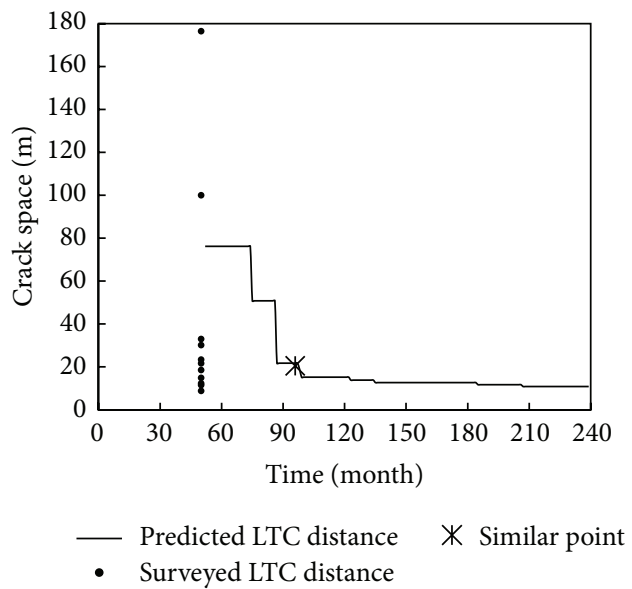

Figure 10: Predicted thermal cracking versus survey thermal cracking on Changping Highway.

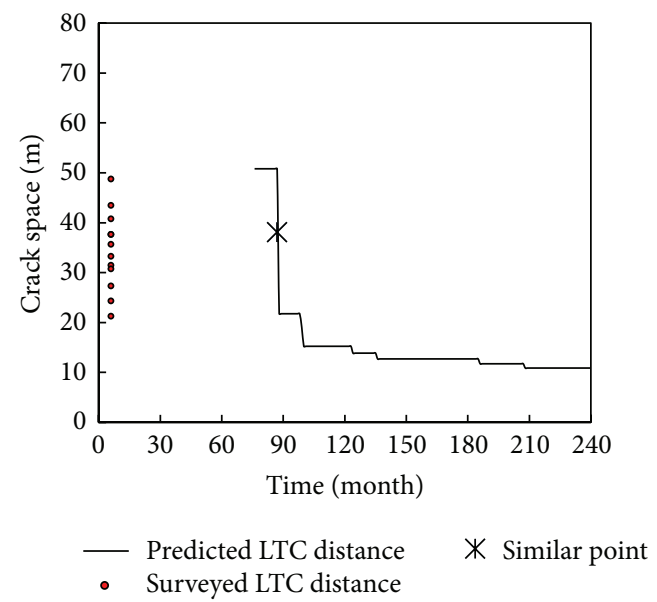

FIGURE 11: Predicted thermal cracking versus survey thermal cracking on Qitai Highway.

Then the predicted thermal cracking space decreased with time ( $38.1 \mathrm{~m}$ after 64 months and $10.1 \mathrm{~m}$ after 184 months). The average surveyed thermal cracking space on Haxihuan highway is $51.96 \mathrm{~m}$ after 30 months since traffic opening, which is close to the predicted thermal cracking space at the 64 th month since traffic opening. Similarly, average surveyed thermal cracking spaces after 48 months and 72 months are $39.2 \mathrm{~m}$ and $34.0 \mathrm{~m}$, respectively, which are close to the predicted thermal cracking spaces at 82 months and 108 months, respectively.

5.4. Calibration. From the comparisons between surveyed cracking and predicted thermal cracking data, it can be seen

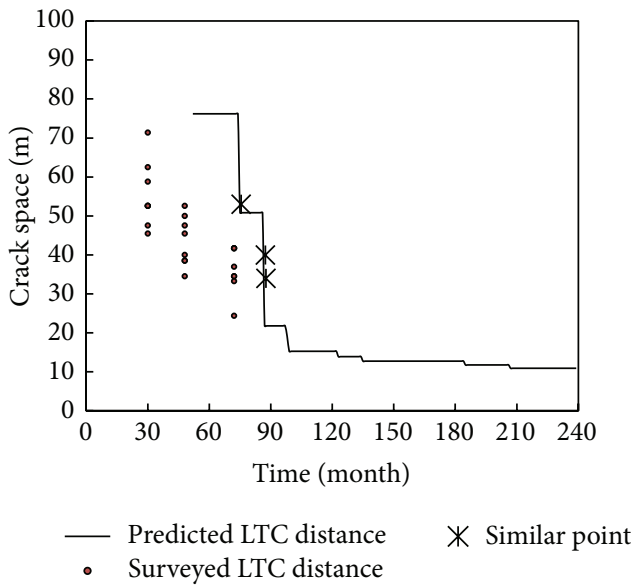

FIGURE 12: Predicted thermal cracking versus survey thermal cracking on Haxihuan Highway.

that the LTC model in MEPDG predicted the initiation and propagation of thermal cracking later than actual situation in field. It can be also seen that the latency of predicted thermal cracking is highly related to the initiation time of predicted thermal cracking, as shown in Table 10. The latency of predicted thermal cracking can be estimated from the following equation:

$$
T_{\text {lat }}=T_{0}-5 \text {, }
$$

where $T_{\text {lat }}$ presents latency time of predicted thermal cracking to actual thermal cracking in field month; $T_{0}$ presents the initiation of thermal cracking, month.

The high-filled subgrade can be seen as one of reasons why the actual low temperature cracking on asphalt pavements in China is more severe than the predicted one in MEPDG. Figure 13 gives the comparison between the predicted cracking and surveyed thermal cracking on Haxihuan Highway after the calibration (1) was applied. It can be seen that the predicted thermal cracking is much closer to the surveyed thermal cracking, though the surveyed data is scattered.

\section{Conclusion}

In order to implement the LTC model in MEPDG in the seasonal frozen region, the northeast of China, sensitivity analyses on factors that influence the LTC model were conducted and the LTC model was calibrated with the surveyed thermal cracking data in that area. It is found that the asphalt binder used in the surface layer is the crucial factor that influences thermal cracking. Then, based on sensitivity analyses on the influences of asphalt layer, base, and other 


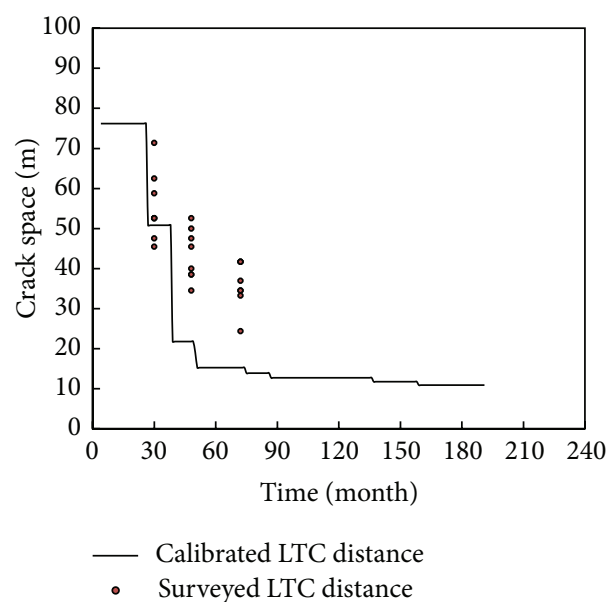

FIGURE 13: Calibrated thermal cracking versus surveyed thermal cracking on Haxihuan Highway.

factors on thermal cracking of asphalt pavement, asphalt pavement structures with good thermal cracking resistance were recommended. The combination of asphalt layers was recommended when the base layers were fixed and vice versa.

The comparison between surveyed cracking and predicted thermal cracking from MEPDG indicates that there is latency for the predicted thermal cracking from MEPDG of about 5 months. After calibration, the LTC model in MEPDG can provide a reasonable prediction on the thermal cracking in the northeast of China.

The approach in this paper to calibrate the LTC model in MEPDG can be helpful when the Pavement ME Design needs to be applied in other areas other than North America.

\section{Disclaimer}

The contents of this paper merely represent the views of the authors who are solely responsible for the facts and the accuracy of the data presented in this paper and do not necessarily reflect the official views or policies of AASTHO or China Ministry of Transportation, and the contents do not constitute a standard, specification, or regulation.

\section{Conflict of Interests}

The authors declare that there is no conflict of interests regarding the publication of this paper.

\section{Acknowledgments}

This study was funded by the China Ministry of Transportation and was completed with MEPDG software version 1.1 prior to the release of AASHTOWare Pavement ME Design software. The authors would like to thank AASHTO for providing the MEPDG software and technical support. This study was supported by National Science and Technology Support Project, 2014BAG05B07.

\section{References}

[1] R. C. Haas, "A method for designing asphalt pavements to minimize low-temperature shrinkage cracking," Asphalt Institute Research Report RR-73-1, 1973.

[2] P. Hao, D. Zhang, and X. Hu, "Evaluation method for low temperature anti-cracking performance of asphalt mixture," Journal of Xian Highway University, vol. 20, no. 3, pp. 1-5, 2000.

[3] J. J. Hajek and R. C. Haas, "Predicting low-temperature cracking frequency of asphalt concrete pavements," Highway Research Record 407, Highway Research Board, Washington, DC, USA, 1972.

[4] H. J. Fromm and W. A. Phang, "A study of transverse cracking of bituminous pavements with discussion," in Proceedings of the Association of Asphalt Paving Technologists, vol. 41, pp. 383-423, 1972.

[5] F. Finn, C. L. Saraf, R. Kulkarni, K. Nair, W. Smith, and A. Abdullah, "Development of pavement structural subsystems," NCHRP Report 291, Transportation Research Board, Washington, DC, USA, 1986.

[6] R. Roque and B. E. Ruth, "Mechanisms and modeling of surface cracking in asphalt pavements," Journal of the Association of Asphalt Paving Technologists, vol. 59, pp. 396-421, 1990.

[7] R. L. Lytton, U. Shanmugham, and B. D. Garrett, "Design of asphalt pavements for thermal fatigue cracking," Intrm Rpt FHWA-TX-83-06+284-4, National Technical Information Service, 1983.

[8] Y. Jenq and J. Perng, "Analysis of crack propagation in asphalt concrete using cohesive crack model," Transportation Research Record 1317, Transportation Research Board, Washington DC, USA, 1991.

[9] J. B. Soares, F. A. Freitas, and D. H. Allen, "Crack modeling of asphaltic mixtures considering heterogeneity of the material," in Proceedings of the 82th Annual Meeting of Transportation Research Board, vol. 1832, pp. 113-120, Transportation Research Board, Washington, DC, USA, 2003.

[10] B. Jongeun and L. A. Imad, "Finite element modeling of reflective cracking under moving vehicular loading: investigation of the mechanism of reflective cracking in hot-mix asphalt overlays reinforced with interlayer systems," in Proceedings of the ASCEs Airfield and Highway Pavements Conference, pp. 7485, Bellevue, Wash, USA, 2008.

[11] Y. Kim, J. Lee, C. Baek, S. Yang, S. Kwon, and Y. Suh, "Performance evaluation of warm- and hot-mix asphalt mixtures based on laboratory and accelerated pavement tests," Advances in Materials Science and Engineering, vol. 2012, Article ID 901658, 9 pages, 2012.

[12] H. Fazaeli, H. Behbahani, A. A. Amini, J. Rahmani, and G. Yadollahi, "High and low temperature properties of FTparaffin-modified bitumen," Advances in Materials Science and Engineering, vol. 2012, Article ID 406791, 7 pages, 2012.

[13] P. Saxena, D. Tompkins, L. Khazanovich, and J. T. Balbo, "Evaluation of characterization and performance modeling of cementitiously stabilized layers in the Mechanistic-Empirical pavement design guide," Transportation Research Record, no. 2186, pp. 111-119, 2010.

[14] AASHTO, AASHTO Guide for Design of Pavement Structure, American Association of State Highway and Transportation Officials, Washington, DC, USA, 1993.

[15] AASHTO, LRFD Bridge Design Specifications, American Association of State Highway and Transportation Officials, Washington, DC, USA, 4th edition, 2008. 
[16] L. T. Glover and J. Mallela, Guidelines for Implementing NCHRP 1-37A ME Design Procedures in Ohio: Volume 4-MEPDG Models Validation \& Recalibration, Volume 9: FHWA/OH-2009, Ohio Department of Transportation, 2009.

[17] J. P. Aguiar-Moya, A. Banerjee, and J. A. Prozzi, "Sensitivity analysis of the MEPDG using measured probability distributions of pavement layer thickness," in Proceedings of the 88th Annual Meeting of Transportation Research Board, Transportation Research Board, Washington, DC, USA, 2009.

[18] C. Zhou, B. Huang, X. Shu, and Q. Dong, "Validating MEPDG with tennessee pavement performance data," Journal of Transportation Engineering, vol. 139, no. 3, pp. 306-312, 2013.

[19] D. Ayyala, G. R. Chehab, and J. S. Daniel, "Sensitivity of M-E PDG level 2 and 3 inputs using statistical analysis techniques for New England states," in Proceedings of the 89th Annual Meeting of Transportation Research Board, Transportation Research Board, Washington, DC, USA, 2010.

[20] A. Banerjee, J. Aguiar-Moya, and J. Prozzi, “Texas experience using LTPP for calibration of the MEPDG permanent deformation models," in Proceedings of the 88th Annual Meeting of Transportation Research Board, vol. 2094, pp. 12-20, Transportation Research Board, Washington, DC, USA, 2009.

[21] M. I. Souliman, M. S. Mamlouk, M. M. El-Basyouny, and C. E. Zapata, "Calibration of the AASHTO MEPDG for flexible pavement for arizona conditions," in Proceedings of the Transportation Research Board 89th Annual Meeting, 10-1817, p. 22, Transportation Research Board, Washington, DC, USA, 2010.

[22] S. Kim, H. Ceylan, K. Gopalakrishnan, O. Smadi, C. Brakke, and F. Behnami, "Verification of mechanistic-empirical pavement design guide (MEPDG) performance predictions using pavement management information system (PMIS)," in Proceedings of the 89th Annual Meeting of Transportation Research Board, vol. 2153, pp. 30-39, Transportation Research Board, Washington, DC, USA, 2010.

[23] China Geological Environmental Monitoring Institute, "The groundwater monitoring site map," Groundwater table, 2013, http://219.142.70.139/dxs/.

[24] M. Oman, "MnROAD traffic characterization for the mechanistic-empirical pavement design guide using weighin-motion data," in Proceedings of the Transportation Research Board 89th Annual Meeting, 10-2903, p. 19, Transportation Research Board, Washington, DC, USA, January 2010.

[25] C. E. Zapata, D. Andrei, M. W. Witczak, and W. N. Houston, "Incorporation of environmental effects in pavement design," Road Materials and Pavement Design, vol. 8, no. 4, pp. 667-693, 2007.

[26] C. E. Zapata, "Considerations of climate in the new AASHTO mechanistic empirical-pavement design guide," in Proceedings of the 88th Annual Meeting of Transportation Research Board, Transportation Research Board, Washington, DC, USA, 2009. 

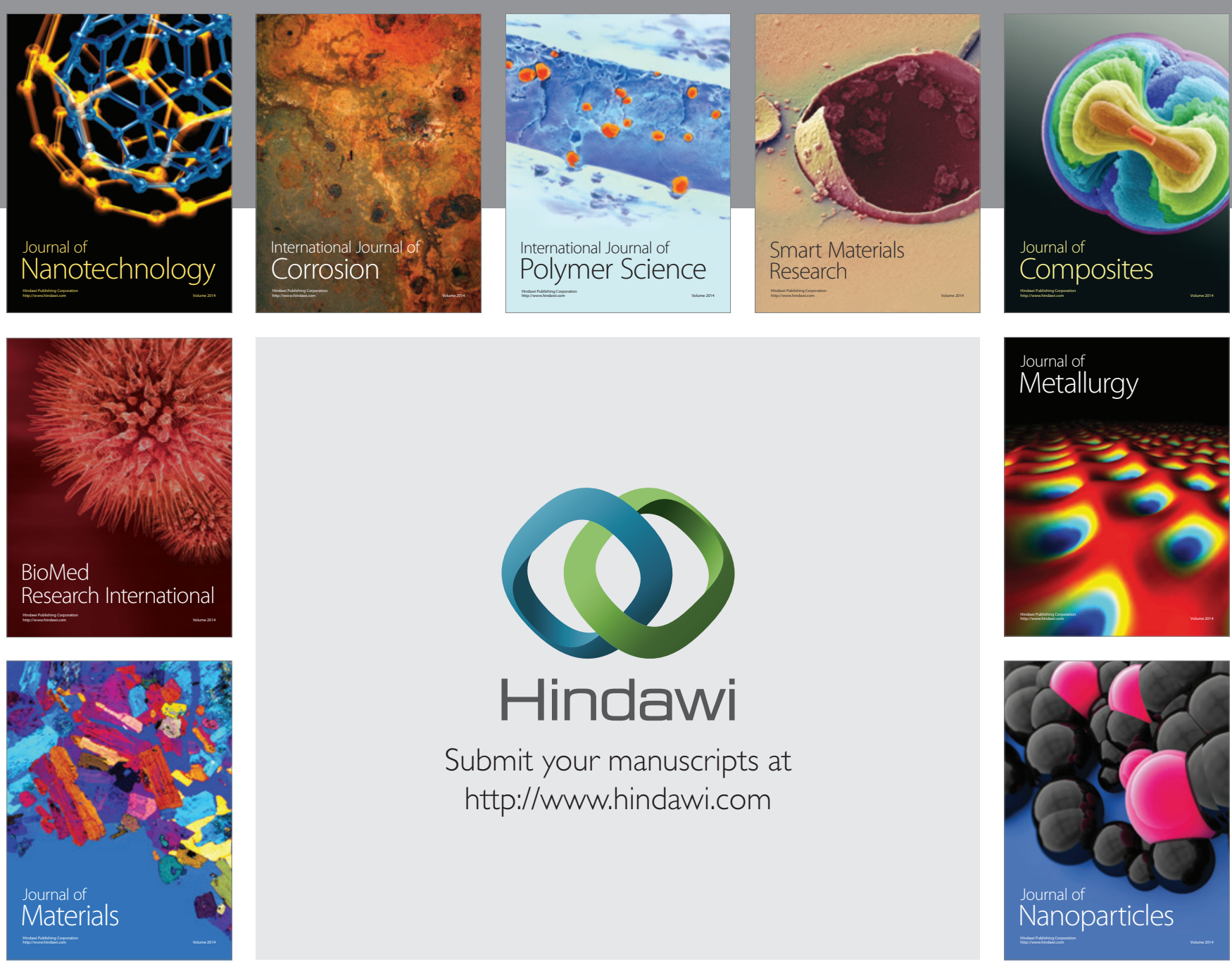

Submit your manuscripts at http://www.hindawi.com
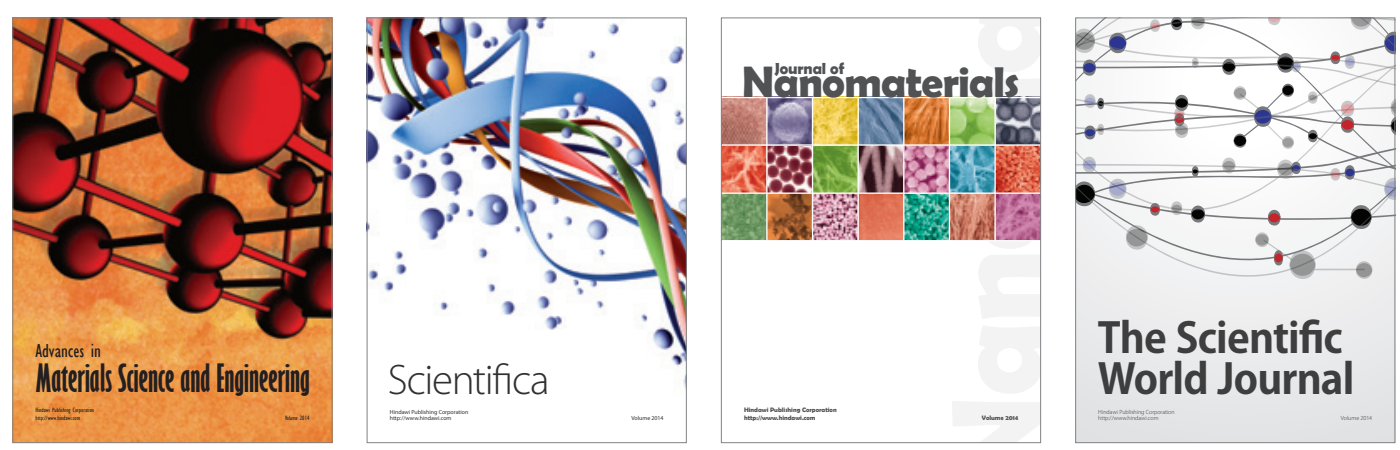

\section{The Scientific World Journal}
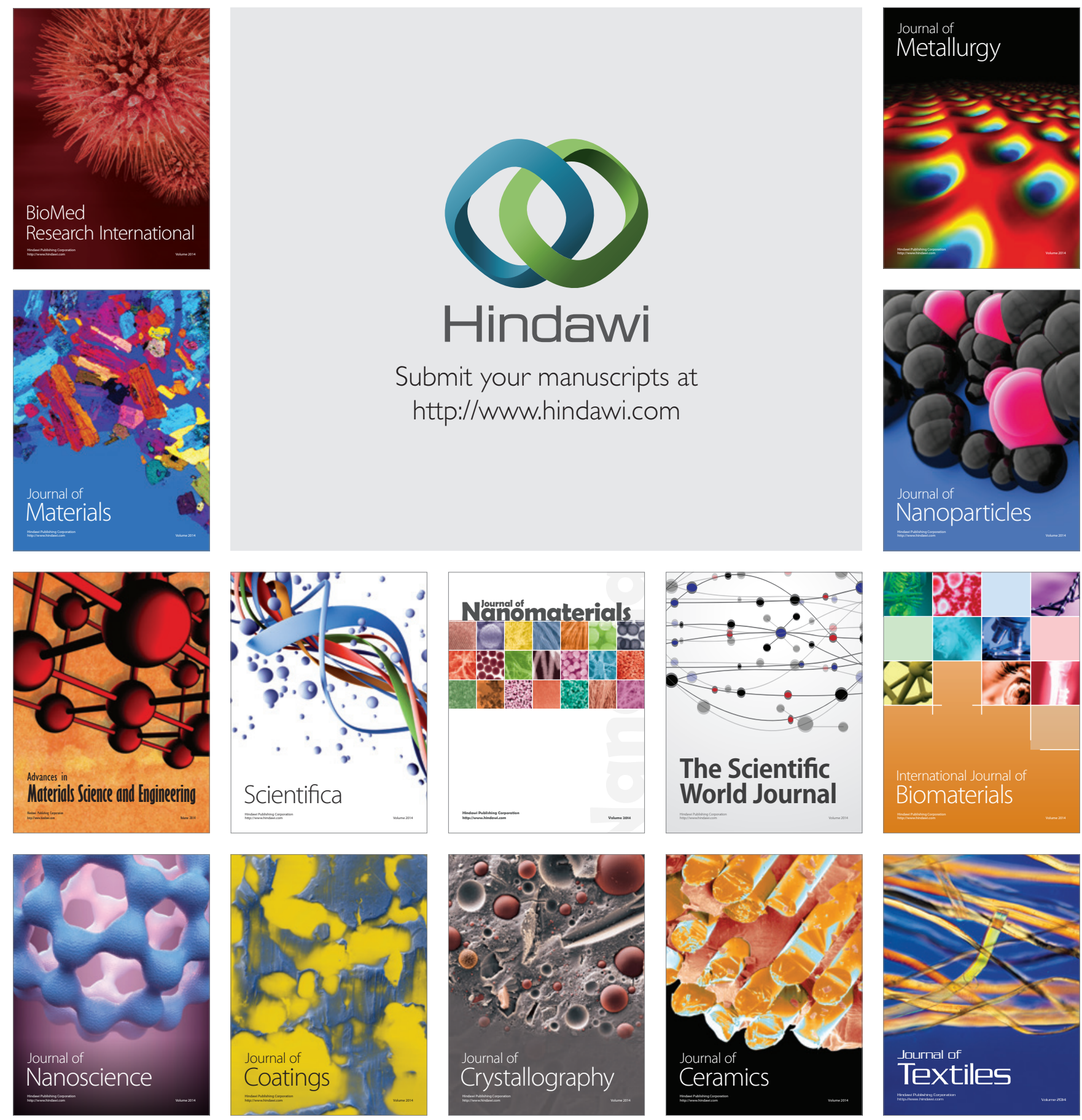